\title{
Research on Online Education Interactive Application Based on Cloud Computing and Large Data \\ XU Guo ${ }^{1, a}$
}

${ }^{1}$ China West Normal University, Education Information Technology Center,Nanchong, Sichuan, 637000 China

a11010486@qq.com

Keywords: Online education interactive platform; cloud computing; big data

\begin{abstract}
Online education interaction is an important field of online education research. The emergence and development of cloud computing and big data technology have brought new opportunities for online education interaction research and have a tremendous impact on data processing and service methods. On the basis of expatiating on the connotation characteristics of cloud computing and big data, this paper analyzes the problems faced by online education interaction and builds an online education interaction platform model based on big data and cloud computing to achieve a high level of interaction, and summarizes the utilization cloud computing and big data online education interactive platform features advantages.
\end{abstract}

\section{Introduction}

With the continuous deepening of the impact of the Internet on people's life, learning and communication, online education has begun to enter people's perspectives. Through the application of information technology and Internet technology to carry out content dissemination and fast learning method, it has the advantage of highly sharing learning resources, teachers and students across the two-way interaction between time and space, and learning autonomy. The level of interaction achieved by learners through interactive media directly affects the level of knowledge construction of learners, which determines the success of online learning. However, with the deepening of the interaction, online education interactive platform model based on big data and cloud computing support is constructed to realize the perfect online interaction and solve the problems in the current online education.

\section{System Design of Online Education Interactive Platform Based on Cloud Computing and Big Data}

A. Google File System and GAE Development Environment

(1) Google File System (GFS) was developed by Google, which is built to meet the needs of rapidly growing data and growing data storage, and it was built on a host of inexpensive servers. Figure 1 GFS Overall Architecture Diagram:

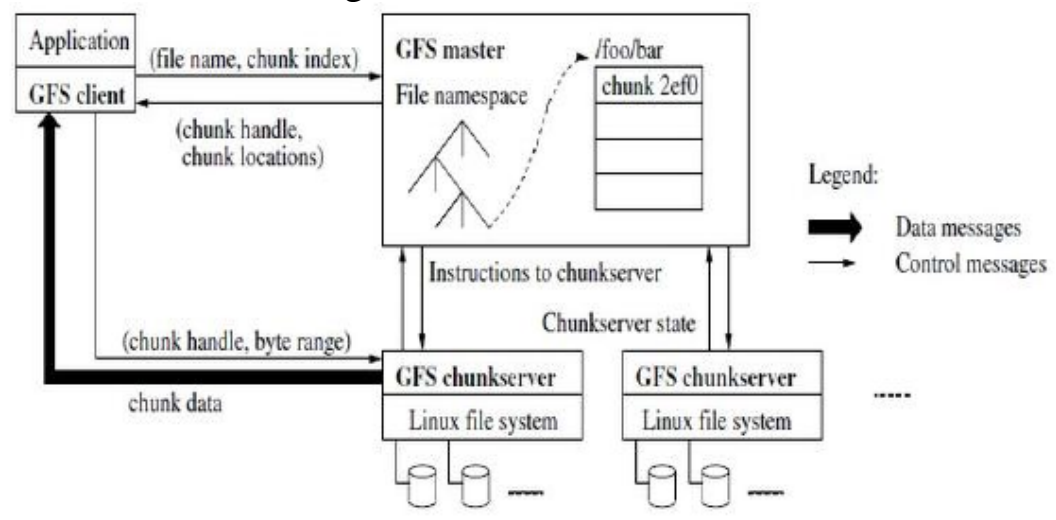

Figure 1 GFS Overall Architecture Diagram 
GFS divides the nodes of the entire file system into three roles: client, master, and block server. The client is the access interface that GFS provides to the application, which is a set of proprietary interfaces that do not comply with the POSIX specification and are provided in the form of library files. The application calls these library functions directly and links with the library.

(2) GAE Development Environment

GAE is a platform for web application development and hosting in Google-managed data centers. This article's online education platform will be built on GAE because GAE is an open source platform that is a free hosting space. And not only that, we can take full advantage of Google's massive server cluster to provide enough space for our online education platform, bandwidth and resources and so on. In this way, the defects of the traditional online education platform are fundamentally solved. GAE provides some very powerful storage methods. Because its design itself takes scalability into consideration, GAE supports two main storage methods: The Datastore (or Bigtable) is responsible for storing regular data that you normally save to a database, while Blobstore is responsible for storing large binaries. Both methods have fixed access times, and they are completely different from the file systems that you may have operated in the past. In addition to these two methods, there is a new method of combining these two methods: Google Storage for Developers. It works like Amazon S3, which is also very different from the traditional file system. Figure 2 shows the difference between one and two Web service calls.

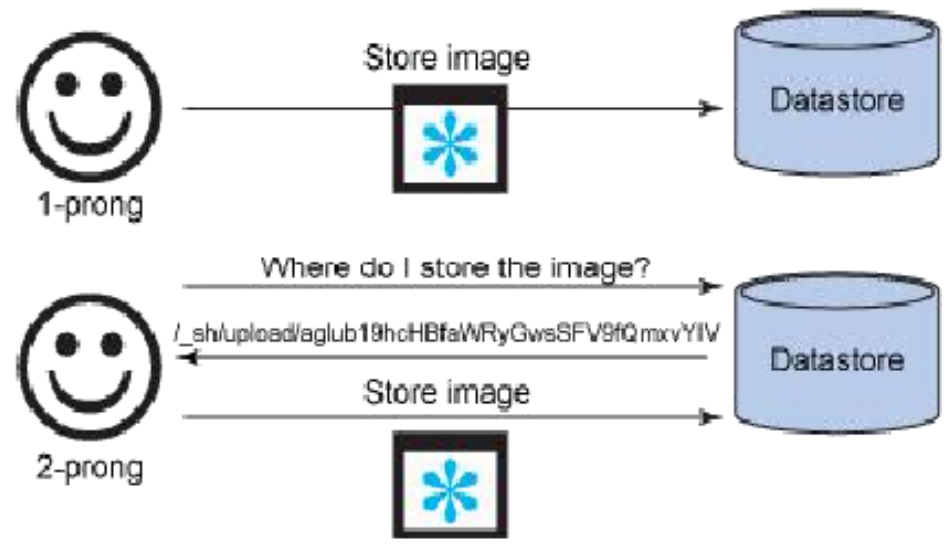

Figure 2 the Difference between One and Two Web Service Calls

B. System User Function Requirements

According to the user's point of view of the functional requirements of the entire online education platform for systematic analysis, the main users of the system include trainees, teachers and administrators.

(1) Students functional needs analysis. Students log in to the system and conduct related online education activities, mainly include: a. Notice View: When students log on to the system, they can view the system announcement issued by the administrator and understand the latest developments in the system in time. b. Online Learning: Students can choose their favorite courses and related learning materials according to their actual needs. c. Online test: Students can test the knowledge that they have learned through the online exam and find the missing information in time. d. Station Mail: Students can send emails to other students in the system to communicate with others while they are studying. e. File Upload: Students can upload their own study notes or some excellent learning resources to the system server for their own learning. f. Download Resources: Students can download learning resources on the server to their own database.

(2) Teacher Functional Requirements Analysis. a. Publish course information: Teachers log in to the system, post the latest course information and start time. b. Upload learning resources: Teachers can upload their own courseware, syllabus and classroom notes and other learning materials to the system's server for effective learning. c. Download learning resources: Teachers can download other people's learning resources directly from the system's server to master the latest technological developments. d. Online exams: Teachers can make test papers online. e. Online Classroom: Teachers can teach online class participation in online classrooms. f. Online Communication: Teachers can communicate online with students and answer questions from students. 
C. Database Design

(1) Data flow diagram is mainly elaborated the software system components and the data dictionary is mainly based on the data flow diagram to give the exact meaning of each component. The data dictionary definition of the components of online education system based on cloud computing is shown in Table 1.

Table 1 Online Education System Based on Cloud Computing Data Dictionary

\begin{tabular}{|l|l|l|}
\hline \multicolumn{1}{|c|}{ Name } & \multicolumn{1}{|c|}{ Description } & \multicolumn{1}{c|}{ Definition } \\
\hline $\begin{array}{l}\text { Administrator } \\
\text { Table }\end{array}$ & $\begin{array}{l}\text { Record administrator information so that } \\
\text { learning materials can be recorded information, } \\
\text { query, modify, file upload and download. }\end{array}$ & $\begin{array}{l}\text { Administrator Information = ID } \\
\text { + Account + Password + Create } \\
\text { Date + Administrator Name + } \\
\text { Last Login }\end{array}$ \\
\hline $\begin{array}{l}\text { Learn } \begin{array}{l}\text { Document } \\
\text { Resource } \\
\text { Table } \\
\text { Structure }\end{array} \\
\begin{array}{l}\text { Message } \\
\text { Structure }\end{array}\end{array}$ & Record learning document resource information \\
\hline $\begin{array}{l}\text { Notice } \\
\text { Structure }\end{array}$ & Record user's message & $\begin{array}{l}\text { Learning Document Resource } \\
\text { Information = D + Name + } \\
\text { Uploader ID + Resource URL } \\
\text { + Creation Date }\end{array}$ \\
\hline
\end{tabular}

Table 2 Student Login Information Form

\begin{tabular}{|c|c|c|c|c|}
\hline Field name & Type & Length & Allow blank or not & Description \\
\hline User id & bigint & 8 & NO & Student ID \\
\hline User name & Varchar & 40 & NO & Username \\
\hline User_passwor & Varchar & 20 & NO & Password \\
\hline User createdat & date & 20 & NO & Creation Date \\
\hline
\end{tabular}

Table 3 Administrator Login Information Table

\begin{tabular}{|c|c|c|c|c|}
\hline Field name & Type & Length & Allow blank or not & Description \\
\hline Manager_id & bigint & 8 & NO & Administrator ID r \\
\hline Manager-name & Varchar & 40 & NO & Username \\
\hline Manager pwd & Varchar & 20 & NO & Password \\
\hline
\end{tabular}

Table 4 Resource Information Table

\begin{tabular}{|c|c|c|c|c|}
\hline Field name & Type & Length & $\begin{array}{c}\text { Allow blank or } \\
\text { not }\end{array}$ & Description \\
\hline file_id & bigint & 8 & NO & Document ID \\
\hline File_name & Varchar & 40 & Yes & File Name \\
\hline File_length & Varchar & 20 & Yes & File Size \\
\hline File_description & Varchar & 100 & Yes & $\begin{array}{c}\text { Summary of } \\
\text { Contents }\end{array}$ \\
\hline File_title & Varchar & 50 & Yes & Document Title \\
\hline File_ext & Varchar & 20 & Yes & Extension Name \\
\hline File_typel & Varchar & 20 & Yes & File Type 1 \\
\hline File_type2 & Varchar & 20 & Yes & File Type 2 \\
\hline File_type3 & Varchar & 20 & Yes & File Type 3 \\
\hline
\end{tabular}

Table 5 Resource Upload Information Table

\begin{tabular}{|c|c|c|c|c|}
\hline Field name & Type & Length & $\begin{array}{c}\text { Allow blank or } \\
\text { not }\end{array}$ & Description \\
\hline file_id & bigint & 8 & NO & Student ID \\
\hline File_id & bigint & 8 & NO & Document ID \\
\hline upload_time & datetime & 7 & Yes & Student ID \\
\hline
\end{tabular}


Table 6 Resource Upload Information Form

\begin{tabular}{|c|c|c|c|c|}
\hline Field name & Type & Length & $\begin{array}{c}\text { Allow blank or } \\
\text { not }\end{array}$ & Description \\
\hline file_id & bigint & 8 & NO & Student ID \\
\hline File_id & bigint & 8 & NO & Username \\
\hline down_time & datetime & 7 & Yes & Download time \\
\hline
\end{tabular}

\section{Online Interactive Platform Application Advantages}

A. To achieve personalized precision services for different users from the resource-based online education platform to the user-centered personalized online education platform in the process of building, the most important change is for different users to provide different personalized services. The application of cloud computing and big data has strengthened the research of online education platform users and the analysis and utilization of interactive data. Based on the analysis results, the Company improved the service content, enhanced the quality of personalized service, and completed the platform's follow-up service, accurate service, knowledge related service and promotion service for users. Online education interactive platform through the collection, sorting, analysis, mining and aggregation of user data, macroscopically analyze the development trends and hot spots in related fields to ensure the real-time and cutting-edge learning content.

B. With the development of online education and interactive platforms, the amount of information and data grows rapidly, but the storage requirements for unlimited data storage capacity and reliable data security are stricter. The advent of cloud computing enables the storage and computing of massive data to be solved, and the distributed storage can continuously collect large amounts of data. The online education interactive platform uses the "cloud storage" method to ensure the reliability of the stored data and can be updated in real time, so as to effectively solve the query and management problems of massive data resources.

C. Improve online interactive platform management capabilities, the application of cloud computing and big data online interactive platform, for specific application data requirements, the response is fast, timely and effective. Due to the change and growth of demand, the platform has better performance expansion space and can efficiently handle many types of data. Based on the platform, online education institutions can utilize the advantages of cloud computing technology and big data to fully tap the value of their data. Based on the above algorithm, the improved cosine similarity calculation method subtracts the average score which user has evaluated teaching resources from the score of the evaluation matrix, that is, the rating of the teaching resource is corrected based on the user's rating, and if you rate your other teaching resources generally high, you need to subtract more points to make the score more objectively compliant and vice versa. The formula is as shown in Formula 1:

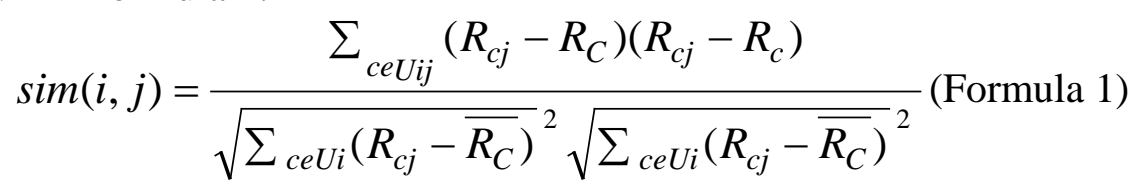

Count user online education in online video viewing time Tu and the total time of the video Ts, and calculate the completeness of the user's watch video, as shown in Formula 2:

$$
\text { itg }=\frac{\mathrm{Ts}}{\mathrm{Tu}} \text { (Formula 2) }
$$

Suppose the user rating matrix calculated as $\left[\mathrm{A}_{1}, \mathrm{~A}_{2}, \ldots, \mathrm{An}\right], \mathrm{Ai}=(\mathrm{B} 1 \mathrm{i}, \mathrm{B} 2 \mathrm{i}, \ldots$ (Bmi) $\mathrm{T}$ represents the user and the scores of the first user for the $m$ items were $B 1 i, B 2 i, \ldots, B m i$, The predictive score can be obtained by using the co-occurrence matrix obtained from Section 5.3.2 . The formula for Cij is shown in Formula 3:

$$
C_{i j}=\frac{\sum_{1}^{m} n_{i k} B_{k j}}{\sum_{1}^{m} n_{i k}}(\text { Formula } 3)
$$




\section{Conclusion}

The emergence of cloud computing and big data technology not only affects the form of online educational interaction, but also provides new ideas and methods for interactive information analysis. On the one hand, the new technology makes the interactive behavior develop continuously in the direction of real-time and fragmentation, making the interactive process more and more complicated; On the other hand, the new technology makes it possible to obtain a large amount of interactive data, especially behavioral data, so as to provide decision-making basis for online learning and teaching. Online education as an information service, despite the advantages of online educational interactive platform resources, but its technical and other disadvantages also limits its development. Therefore, the author builds an online education interaction platform model based on big data and cloud computing, enabling online learners and teachers to achieve perfect online interaction activities and enhance the core competitiveness of online interaction.

\section{References}

[1] Jia Jingdian. Online Interactive Applications on Cloud Computing and Big Data [J] Science and Technology Innovation and Application, 2016(33):88.

[2]Hu Suyao. Research on Interactive Application of Online Education Based on Big Data and Cloud Computing [J] Computer Knowledge and Technology, 2016, 12((32):239-240.

[3] Qiu Hongwei. Personal Education Based on Real Time Evaluation of Cloud Computing and Big Data Environment [J] Journal of Taiyuan Urban Vocational and Technical College, 2017(04):172-174.

[4] Yang Fei. Application Analysis of Big Data and Cloud Computing Platform [J] Computer Fans, 2017(01):23.

[5] Li Cheng. Applied Research on Online Education Interaction in Big Data Environment [J] Modern Commerce Industry, 2017(26):168-169. 